3.Нейгауз Г. «Об искусстве фортепианной игры. Записки педагога» М., «Музыка»,1967, 322с.

4. Перельман Н. В классе рояля «Музыка», Лд, 1970, 56c.

\section{ИСПОЛЬЗОВАНИЕ ЧЕК-ЛИСТОВ КАК ИНСТРУМЕНТА ВИЗУАЛЬНОЙ ПОДДЕРЖКИ В РАЗВИТИИ ДЕЯТЕЛЬНОСТИ ПОДРОСТКОВ С РАССТРОЙСТВАМИ АУТИСТИЧЕСКОГО СПЕКТРА}

\author{
Гусева Надежда Юрьевна \\ кандидат психологических наук, руководитель \\ регионального ресурсного иентра по организачии \\ сопровождения детей с РАС, ГБУДО НО «ЦППМСП»
}

г. Нижний Новгород

\title{
USING CHECKLISTS AS A VISUAL SUPPORT TOOL IN THE DEVELOPMENT OF ACTIVITIES OF ADOLESCENTS WITH AUTISM SPECTRUM DISORDERS
}

\author{
Guseva Nadezhda \\ candidate of psychological sciences, head of the \\ Regional Resource Center for Supporting Children with ASD. \\ State-Funded Institution of Supplementary Education \\ Nizhny Novgorod \\ DOI: 10.31618/nas.2413-5291.2020.1.55.210
}

\section{Аннотация}

В данной статье рассматривается некоторые аспекты применения чек-листов как инструмента визуальной поддержки деятельности подростков с РАС. Анализируются основные причины, по которым данный вид визуальной поддержки является наиболее эффективным в реализации продуктивной деятельности обучающихся данной категории.

\section{Abstract}

This article discusses some aspects of using checklists as a tool for visual support of the activities of adolescents with ASD. The main reasons why this type of visual support is the most effective in the implementation of productive activities of students in this category are analyzed.

Ключевые слова: расстройства аутистического спектра; визуальная поддержка; чек-листы; продуктивная деятельность.

Keywords: autism spectrum disorders; visual support; checklists; productive activity.

Визуальная поддержка является наиболее эффективным способом организации деятельности ребенка с РАС. Данный вопрос является одним из самых методически разработанных аспектов в адаптации учебных материалов и социальной среды детей данной категории $[1,3,5]$. Визуальная поддержка сопровождает самые эффективные методы альтернативной коммуникации, визуальных расписаний и визуальных подсказок, используемых в формировании новых навыков [4]. Поскольку сфера визуального восприятия, внимания и памяти у большинства детей с РАС развита достаточно хорошо, по сравнению с аудиальной, данные методы позволяют ребенку быстро приобретать коммуникативные, социальнобытовые и академические навыки. Тем не менее, при эффективной коррекции, начатой в раннем возрасте, ребенок с РАС со временем перерастает даже самые универсальные методики. Очень часто подросток обладает большим количеством компетенций благодаря длительному использованию визуальной поддержки: навыки коммуникации, беглое чтение, определенный уровень академических навыков, быстрая ориентировка в визуально представленных дидактических материалах, таких как конструкторы, паззлы и т.д. Тем не менее, возрастные изменения и социальная среда требуют от него перехода к новым, более взрослым видам деятельности, которые неизменно требуют организации визуальной поддержки. Данный вопрос все еще требует научной и методической проработки в связи с разнообразием интересов и возможностей в деятельности подростков с РАС.

Известно, что аутизм проявляется не только в своих непосредственных дефицитах: нарушении коммуникации и социального взаимодействия, но также сопровождается рядом сложностей, связанных с организацией деятельности. Таким образом, даже для подростка с РАС, обладающего большим количеством навыков, с большой вероятностью нужна помощь в освоении новых видов деятельности. Основные трудности в освоении новой деятельности для людей с РАС обусловлены дефицитами слухового восприятия и удержания инструкции на слух, а также планирования, контроля и оценки результатов собственной деятельности. Данные преграды мы постарались максимально нивелировать в организации деятельности подростков с РАС.

С целью формирования навыков планирования и самоконтроля в продуктивной деятельности подростков с РАC в региональном ресурсном центре по организации сопровождения детей с РАC была разработана программа дополнительного образования по направлению декоративно- 
прикладного творчества. Данная программа была адаптирована с помощью разработки индивидуальных чек-листов, исходя из интересов и возможностей каждого обучающегося. В программе приняли участие 12 подростков от 12 до 15 лет, ранее использовавших визуальное расписание в виде карточек-пиктограмм.

Чек-лист - один из самых современных видов визуальной поддержки продуктивной деятельности людей с РАС. Сам чек-лист представляет собой перечень последовательных действий, которые необходимо выполнить, чтобы получить определенный результат в какой-либо работе. Работа в соответствии с чек-листом предполагает выставление отметки «сделано» у каждого пункта. Особенно данный метод ценен в применении к продуктивной деятельности, так как помогает людям с РАС самостоятельно достигать конечного результата.

Необходимость введения в деятельность чеклистов у данной выборки обосновывается следующим:

- сформированный у данных подростов навык чтения, который позволяет перейти на следующий, более сложный уровень восприятия визуальной инструкции;

- возможность усложнения видов деятельности за счет смыслового расширения инструкции;

- возможность перехода от разрозненных учебных заданий к поэтапной деятельности, обеспечивающей ее конечный результат в виде конкретного продукта.

Для того, чтобы чек-лист обладал практической эффективностью, при его разработки должен был соблюден ряд условий:

- ограниченное количество пунктов (от 5 до10), которое обеспечивало бы поддержание внимания и интереса до завершения работы;

- чёткая и лаконичная формулировка каждого пункта: в каждом пункте должен быть сформулирован промежуточный результат, которого ученик должен достигнуть, чтобы перейти к следующему этапу работы;

- наличие места для пометки «сделано».

Также были определены критерии эффективности чек-листа в отношении каждого пункта для дальнейшего отслеживания динамики:

- понимание и принятие задачи;

- самостоятельность в исполнении;

- время выполнения (динамика);

- скорость переключения с предыдущего пункта и осознание этапа работы: сколько уже выполнено и сколько предстоит (контроль выполнения);

- умение соотносить свой результат с заданным критерием по каждому пункту работы (контроль результата).

Оценочные показатели по данным критериям по трёхбалльной системе (от 0 до 2) представлены в Табл. 1 .

Сравнение средних показателей в начале и конце курса занятий в \%

Табл. 1

\begin{tabular}{|c|c|c|c|c|c|c|c|c|c|c|c|c|}
\hline Пункт чек-листа & \multicolumn{2}{|c|}{1} & \multicolumn{2}{|c|}{2} & \multicolumn{2}{|c|}{3} & \multicolumn{2}{|r|}{4} & \multicolumn{2}{|c|}{5} & \multicolumn{2}{|r|}{6} \\
\hline Критерий & до & после & до & после & до & после & до & после & до & после & до & после \\
\hline принятие задачи & 43 & 63 & 40 & 60 & 36 & 56 & 40 & 60 & 33 & 63 & 36 & 63 \\
\hline самостоятельность & 36 & 63 & 33 & 66 & 40 & 63 & 33 & 60 & 36 & 66 & 33 & 66 \\
\hline динамика & 33 & 53 & 33 & 56 & 30 & 50 & 36 & 53 & 33 & 50 & 33 & 56 \\
\hline контроль выполнения & 33 & 53 & 30 & 50 & 30 & 56 & 33 & 60 & 30 & 53 & 30 & 56 \\
\hline контроль результата & 30 & 50 & 26 & 43 & 33 & 40 & 26 & 43 & 30 & 53 & 33 & 53 \\
\hline
\end{tabular}

Сравнительный анализ полученных результатов в начале деятельности и после 15 занятий по чек-листам показал значительные продвижения подростков не только в освоении навыка работы с чек-листом, но и непосредственно в декоративно-прикладном творчестве.

Наибольших успехов удалось достичь в отношении самостоятельности подростков. Как только обучающиеся поняли алгоритм действия по чек-листу, они стали выполнять задания практически самостоятельно, несмотря на постепенное усложнение заданий.

Также быстро сформировалось принятие задачи: после появления навыка работы по чеклисту, подростки достаточно быстро включались в работу; таким образом, в течении цикла занятий не возникало проблем с включением в деятельность.

Следует отметить сформировавшиеся психологические новообразования у данной выборки: контроль выполнения и контроль результата деятельности. С учетом того, что ранее подростки работали по расписанию, перечисляющему не связанные между собой виды деятельности, например: писать, читать, рисовать, работа по этапам одного вида деятельности, ведущей к выполнению конкретной задачи являлось новым для них опытом. Более того, при условии дальнейшего регулярного получения опыта работы по чек-листам, контроль процесса выполнения и результата деятельности с высокой вероятностью сформируются во внутреннем плане, что позволит в дальнейшем принимать, удерживать и доводить до конца задачу без вспомогательных средств.

Таким образом, данный вид визуальной поддержки позволил не только скомпенсировать дефициты понимания речи, но и на более глубоком уровне проработать навыки планирования, контроля выполнения и оценивания результата своей деятельности.

\section{Список литературы:}

1. Гусева Н.Ю. Применение визуального расписания для детей с РАС в Центре длительной реабилитации «Добрый сад» // Аутизм и нарушения 
развития. 2018. Т. 16. No 2. С. $21-28$. doi: 10.17759/autdd.2018160203

2. Загуменная О.В., Васильева А.В., Кистень В.В., Петрова О.М. Организация среды при обучении детей с РАC // Аутизм и нарушения развития. 2018. Том 16. № 1. С. 13-17. doi:10.17759/autdd.2018160102

3. Линн. И. МакКланнахан., Патрисия Крантц. Расписания для детей с аутизмом. Обучение самостоятельному поведению / Пер. с англ. О Чикурова, С. Морозовой. М.: Изд-во «СигналЪ». 2003. -129 c.
4. Мелешкевич О., Эрц Ю. Введение в прикладной анализ поведения (АВА): принципы коррекции проблемного поведения и стратегии обучения детей с расстройствами аутистического спектра и другими особенностями развития. Самара: Изд. дом «Барах-М». - 2015. - 208 с.

5. Шарова Ю.А. Подготовка и использование расписаний в обучении детей младшего школьного возраста, // Аутизм и нарушения развития. 2015. Том 13. № $3 . \quad$ C. $11-20$. doi:10.17759/autdd.2015130302

\title{
ФОРМИРОВАНИЕ ПРОФЕССИОНАЛЬНОЙ КУЛЬТУРЫ СТУДЕНТА-ПОЛИТОЛОГА
}

\author{
Медовщиков Захар Николаевич \\ Аспирант каф., политологии и соччиологии \\ Воронежский государственный университет
}

Г. Воронеж

\section{FORMATION OF PROFESSIONAL CULTURE OF A POLITICAL SCIENCE STUDENT}

\author{
Z.N. Medovshikov \\ Graduate student \\ Voronezh State University \\ Voronezh
}

\section{Аннотация}

В данной статье определены основные компетенции, которыми должен обладать студент-политолог. Путем экспертного опроса проведено исследование на кафедре политологии и социологии Воронежского государственного университета и выявлен ряд проблем, с которыми сталкиваются преподаватели в процессе подготовки.

\section{Abstract}

This article defines the main competencies that a political scientist should have. An expert survey was made on department of political science and sociology and problems which teachers faced is defined

Ключевые слова: студент-политолог, общекультурные компетенции, профессиональные компетенции, образовательный процесс

Key words: political scientist, general cultural competencies, professional competencies, educational process

Профессия политолога на сегодняшний день является плохо исследованным, но актуальным социальным феноменом. Это обусловлено, прежде всего, потребностью общества повысить качество политико-управленческих решений, принимаемых властными институтами РФ. Подготовка таких решений - это результат деятельности не только политиков, а и квалифицированных аналитиков, экспертов, консультантов и т.д.,

Еще один фактор, актуализирующий рассматриваемую проблему - это потребность формирования и развития гражданской культуры российского общества, в том числе молодежи. Изучение данной проблемы приводит к убеждению, что необходимы дополнительные целенаправленные усилия образовательных учреждений, а также сообщества политологов, чтобы молодежь становилась сознательным участником политической жизни.

На сегодняшний момент в России более 100 университетов готовят студентов по направлению “Политология". Требования, предъявляемые к подготовке студента - политолога прописаны в Федеральном государственном стандарте “Политология" 41.03.04, их можно разделить на 2 большие группы - общекультурные и общепрофессиональные е компетенции. К общекультурным относятся: способность анализировать основные этапы и закономерности исторического развития общества для формирования гражданской позищии; способность использовать основы экономических знаний в различных сферах жизнедеятельности; способность использовать основы правовых знаний в различных сферах жизнедеятельности; способность работать в коллективе, толерантно воспринимая сочиальные, этнические, конфессиональнье и культурные различия; способностью $\kappa$ самоорганизациии $u$ самообразованию;

К общепрофессиональным:

владение базовыми и специиальными знаниями и навыками теоретического и прикладного характера в области политических наук; владение общенаучной и политологической терминологией, умением работать с оригинальными научными текстами и содержащимися в них смысловыми конструкциями; способность к высокой мотивации по выполнению профессиональной деятельности, стремлением к повышению своей квалификации; способность к критическому анализу, обобщению и систематизациии 